\title{
Citizen Science in Educational Institutions: does it require pedagogical embedment?
}

\section{Victoria L. Miczajka ${ }^{a^{\star}}$, Thomas Hübner ${ }^{b}$, Falk Böttcher ${ }^{c}$, Vanessa van den Bogaert $^{d}$, Kim Lange-Schubert ${ }^{\mathrm{a}}$}

a Department of General Sciences Education Teaching and Learning, University of Leipzig, Marschnerstraße 31, Leipzig, Germany

b ZAMG (Zentralanstalt für Meteorologie und Geodynamik), Hohe Warte 38, Vienna, Austria

c DWD (Deutscher Wetterdienst (German Meteorological Service)), Department of Agrometeorology, branch office Leipzig,

Kärrnerstraße 68, Leipzig, Germany

d Department of Research on Learning and Instruction, Ruhr-Universität Bochum, Universitätsstraße 150, Bochum, Germany

E-mail:miczajka@uni-leipzig.de; thomas.huebner@zamg.ac.at; Falk.Boettcher@dwd.de; vanessa.vandenbogaert@ruhr-uni-bochum.de; kim.lange-schubert@uni-leipzig.de

\begin{abstract}
Citizen science (CS) has developed tremendously within the last years with manifold variations of arrangements. Each of these arrangements focuses on its own concerns and objectives. To better understand different expectations and needs of different CS arrangements further research need to be done, especially when using CS in educational institutions with high pressure on pedagogical added value. Here, we present our empirical study approach examining possible benefits for student teachers (ST) as former multipliers in elementary schools participating in an exemplarily CS project.
\end{abstract}




\section{CS: aspiration and impact}

Within the last decade CS gained more and more attention at least due to improved communication technologies and more global thinking which consequently leads to a further understanding of the whole idea of CS itself. Various benefits for participation are frequently highlighted and the idea and approach of CS promises to create added values in many aspects: improved understanding and acceptance of science, extended data capturing, increased interest in scientifically research [4] or even a more supportive attitude and contribution towards sustainability [6] are only a few benefits that are discussed in this context. However, can all these values be achieved automatically just by doing CS, by being part of a project? Which are the felicity conditions that might be necessary to achieve specific benefits?

A short literature review emphasizes the need for more research to answer by empirical evidence the following questions: happen these benefits randomly or incidentally just by being part of a project? And is additional effort necessary to outreach these benefits (which is hardly comprehensively evaluated [e.g. 1, 5, 8], especially not for young participants [e.g. 3]).

Hitherto most CS projects arose mainly in the disciplines of natural sciences with a specific interest for data capturing and no particular focus on participants' motivation or learning outcome. Consequently, one could assume that possible benefits for CS participants could be random, happen incidental or just ideally in dependence to the skills underlying the project participation itself. Furthermore teachers as multipliers have the specific responsibility in teaching (citizen) science components, so their own first-hand experience might even be more important and meaningful.

We endorse the definite need for more research and empirical evidence on motivations, attitudes, learning outputs and possibly correlated other values due to CS participation especially when applying it in educational institutions. Further, we highly recommend further research on distinguishing whether CS projects use extra pedagogical embedment to increase possible benefits for the citizen scientists. Added particular pedagogical embedment might not only be advantageous for researchers' interest on data quality but for citizen scientists as projects might be better attuned and more transparent on its outreach for all those that are involved (compare e.g. [7]). Furthermore, a better categorization and distinction of possible outcomes of the projects could help to support a better orientation or an ideal fit for all participants in an extremely fastgrowing variety of CS projects. Moreover, transparency in the specialist discipline like biodiversity, history or geology, might be combined with a comprehensible communication of the possible outcome for the citizen scientists as clear as the intended research aims. For example, a project might offer to sensitize citizen scientists' awareness and attitude towards human responsibility of climate change sustainably next to specific data capturing techniques i.e. on temperature, carbon dioxide emissions or precipitation. We would like to put this for a broader discussion, as empirical evidence on these "byproduct" interests or creation is still hardly tested or published.

For our research it is of interest, whether CS participation "only" leads towards a better understanding of the nature of science or (spontaneous) sustainable mind-, knowledge-, or attitude-changes, or which structures or felicity conditions should be considered to achieve these outcomes. Here, we should differ if a better understanding "only" is achieved or if this improved 
metaknowledge can also be actively reflected and forwarded, in the (student) teachers' case to pupils. Furthermore, it is of interest to us, whether at least basic pedagogical embedment is necessary or significantly supportive to gain general understanding or interest of interdependencies of such as for example causes of the anthropogenic climate change or reasons for sustainability transitions. Therein, we see particular importance in how citizen scientists are integrated into CS as projects vary within its demands in tasks, time effort, scale or complexity to name only a few parameters.

Within our research we focus on the questions as explained above, whether CS participation "only" leads towards various personal changes by citizen scientists and whether at least basic pedagogical embedment is necessary to gain these personal benefits sustainably. Our approach is to use an established "contribute project" [compare 7], as it seems that most of the common projects use this form of participation. Therefore, we focus on CS in educational institutions, in our case at university teacher education with the specialization general sciences education. Here, we pay special attention to the pedagogical concept of scientific inquiry in the context of natural sciences as this methodology has been used for long-term in higher teacher education [2]. Our examined CS project is about plant phenology as a helpful instrument to illustrate the complex phenomena of climate change. The observation of beginning of flowering or maturity from so called indicator plants generate important information when compared with historical data about a change in climate. These observations, so far mainly made by scientists and hobby meteorologists, attract more interest in the broader society due to CS projects such as those from "Deutscher Wetterdienst" (DWD, www.dwd.de/phaenologie) or "Zentralanstalt für Meteorologie und Geodynamik" (ZAMG, www.phenowatch.at). At the University of Leipzig, we expect that the pedagogical approach of scientific inquiry in the context of natural sciences' teacher education might be promising to combine scientific data capturing with pedagogical learning on science and a particular scientifically topic itself. Within our research we capture different variables such as motivation, interest or the understanding of nature of science from ST participating in a plant phenology CS project. These data are captured in a treatment-control group design at different time lapse (pre-, post-, follow-up test surveys). Our intended aim is to determine possible benefits within the combination of higher education and scientifically data gathering, which might include an improved sensitivity on the current climate change concerns. In lectures, ST combine their own plant phenology observations with the development of a scientifically research question that should be answered due to their further research. Hereby we integrate ST as citizen scientists as they will later on integrate their own students into CS. Further, we expect ST to reflect their own learning process becoming more sensitive for the learning challenges of the pupils. Additional to the scientifically focus on natural sciences, ST are asked to design prospective lessons for their future work at school. Our research approach is tested in cooperation between DWD, ZAMG, ST and elementary schools. 


\section{References}

[1] Geoghegan, H., Dyke, A., Pateman, R., West, S. \& Everett, G. (2016). Understanding motivations for citizen science. Final report on behalf of UKEOF, University of Reading, Stockholm Environment Institute and University of the West of England.

[2] Huber, L. (2019). «Forschende Haltung» und Reflexion: Forschendes Lernen als Thema, Ziel und Praxis der Lehrerinnen- und Lehrerbildung. In M. Knörzer, L. Förster, U. Franz \& A. Hartinger (Hrsg.), Forschendes Lernen im Sachunterricht (S.19-35). Bad Heilbrunn: Klinkhardt.

[3] Kelemen-Finan, J., Scheuch, M., Winter, S. (2018). Contributions from citizen science to science education: An examination of a biodiversity citizen science project with schools in Central Europe. International Journal Science Education, 40, 2078-2098.

[4] Pettibone, L., Vohland, K., Bonn, A., Richter, A., Bauhus, W., Behrisch, B. et al. (2016). Citizen Science für alle - eine Handreichung für Citizen Science Akteure. Berlin: GEWISS-Konsortium.

[5] Phillips, T.B., Ballard, H.L., Lewenstein, B.V., and Bonney, R. (2018). Engagement in science through citizen science: Moving beyond data collection. Science Education, 45, 369.

[6] Sauermann, H., K. Vohland, K., Antoniou, V., Balázs, B., Göbel, C., Karatzas, K., Mooney, P., Perelló, J., Ponti, M. and Samson, R. (2020). Citizen Science and Sustainability Transitions. Research Policy 49 (5): 103978.

[7] Shirk, J. L., Ballard, H. L., Wilderman, C. C., Phillips, T., Wiggins, A., Jordan, R., McCallie, E., Minarchek, M., Lewenstein, B. V., Krasny, M. E. and Bonney, R. (2012). Public participation in scientific research: a framework for deliberate design. Ecology and Society 17(2): 29.

[8] Turrini, T., Dörler, D., Richter, A., Heigl, F., and Bonn, A. (2018). The threefold potential of environmental citizen science: Generating knowledge, creating learning opportunities and enabling civic participation. Biol Conserv225: 176-186. 